Session \# 2004-221

\title{
Teaching Basic Control Systems Theory Using Robots
}

\author{
Dugan Um, Vedaraman Sriraman \\ Technology Department, Texas State University-San Marcos \\ San Marcos, Texas 78666
}

\begin{abstract}
Automatic control systems and industrial robotics are amongst some very important content areas for Manufacturing Engineering and Engineering Technology students. From a learning processes standpoint there are issues with the way by which these topics are typically delivered in the classroom. First, controls theory is presented using the analytical approach; which causes the subject to appear very "dry" and theoretical. Secondly, control systems and robotics are taught in separate courses, which may result in students not being able to appreciate the interrelationship that exits between these areas. In this paper a strategy is detailed wherein the authors have used a "hands-on" approach, using robots as a tool for communicating key concepts in control systems. The use of robots as a tool also enables students to "discover" the relationship between the two areas.
\end{abstract}

\section{Introduction}

This paper deals with pedagogical problems that were encountered in teaching automation, robotics, and controls systems to engineering technology and manufacturing engineering students at Texas State University-San Marcos. Controls theory as presented in classical books such as those by Kuo ${ }^{1}$ and Ogata ${ }^{2}$ has the potential of coming across as being very mathematical, theoretical, abstract and dry. This is not to suggest that no practical applications are presented in traditional books. However, the applications are typically covered through the medium of such system representations as differential equations, block diagrams, and transfer functions. Thus, students do not develop a real "feel" for the practical applications.

The aforementioned approach is not particularly suitable for engineering technology and manufacturing engineering students (in contrast to mechanical, electrical, and chemical engineering students) as both majors are very intensely processes and equipment oriented, applications engineering disciplines. A survey of the transactions of the ETD listserv ${ }^{3}$ will reveal that several educators face the dilemma of how best to teach controls systems. A second problem that we faced is as follows: Our curriculum requires students to take both TECH 4391 Computer Aided Manufacturing and MFGE 4376 - Control Systems and Instrumentation.

TECH 4391 deals with computer numerical control, robotics, and PLCs, while MFGE 4376 deals with open loop systems, closed loop systems, sensors, actuators, transient response, frequency response, and stability. While both classes present very important materials, students were not able to make the connections between the two. Students are required to take MFGE 4376 before TECH 4391, so that they have foundational controls theory before dealing with computer aided manufacturing. However, students in MFGE 4376 were not able to see an immediate practical need for the course. Therefore, we decided to use robot systems (robot manipulator and its sensor and actuator based accessories) to teach controls theory. 


\section{Our Approach - The Equipment}

The key approach of this paper was to use multi-degree, robot manipulators as a vehicle for demonstrating the practical aspects of automatic control theory. Robots were chosen for a variety of reasons. First, robots being dynamic, came across to students as "cool" pieces of equipment. Secondly, the use of robots automatically established for the students the practical relevance of the theory. Lastly, the operation of robot includes the consideration of sensors, actuators, controllers, and dynamic stability. Thus, they naturally encompassed the many ingredients of a control system.

The robots used in our approach are shown in Figures 1, 3, and 4. Figure 1 illustrates a stepper motor driven, open loop control based robot with an articulated arm configuration. Figure 2 shows a cross section of the robot that reveals the stepper motors. Figure 3 illustrates a pneumatically driven, "bang-bang" robot whose operational sequence was controlled by a programmable logic controller (PLC). This robot was equipped with end of travel limit switches and air-solenoids that operated pneumatic cylinders.

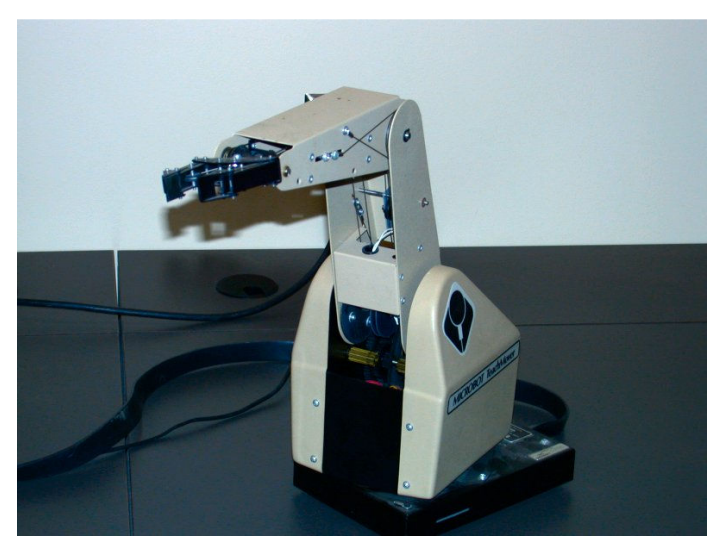

Figure 1. Microbot

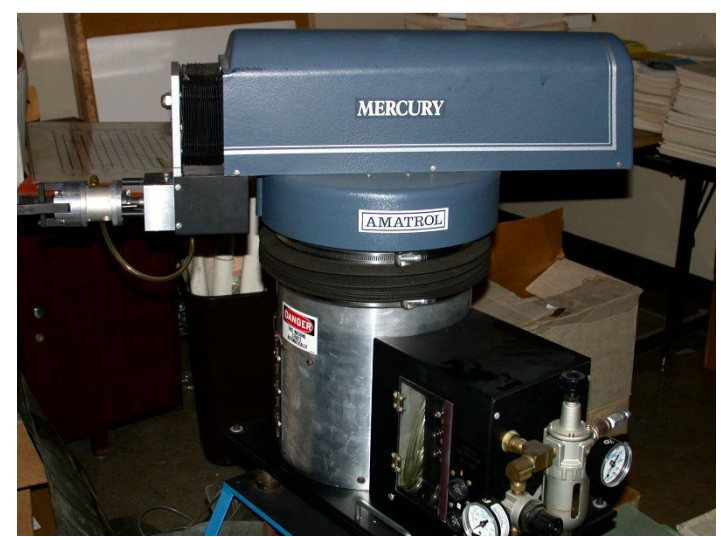

Figure 4. Bang-Bang Robot

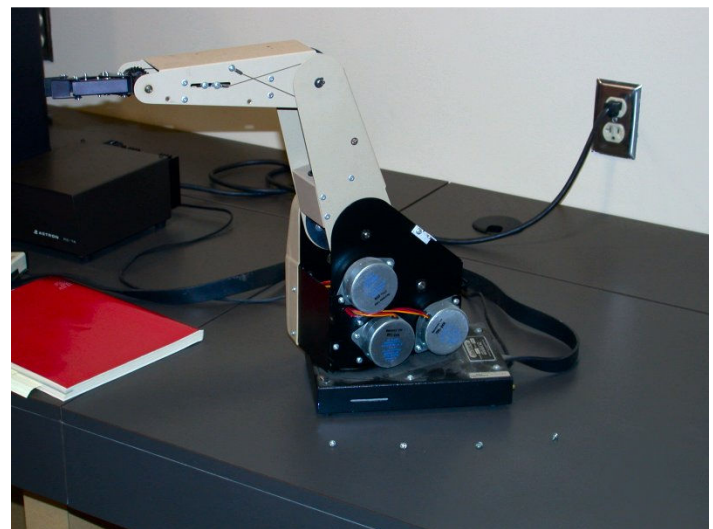

Figure 2. Microbot Actuator with Stepper Motors

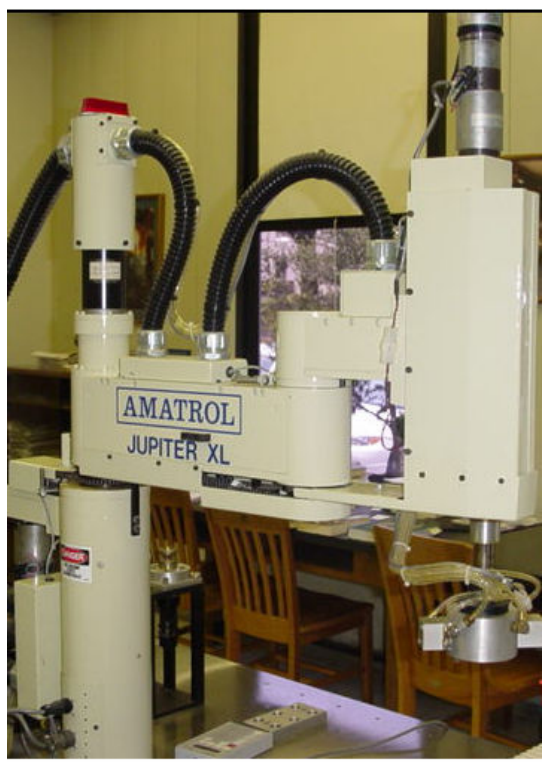

Figure 3. Scara Robot 
Figure 4 illustrates a de servomotor driven, closed loop control based robot with a selective compliance articulated robot arm (SCARA) configuration. This robot was equipped with proximity switches (illustrated in Figure 5) and optical encoders (illustrated in Figure 6). The next section details the laboratory experiences and the procedural approach that we had utilized.

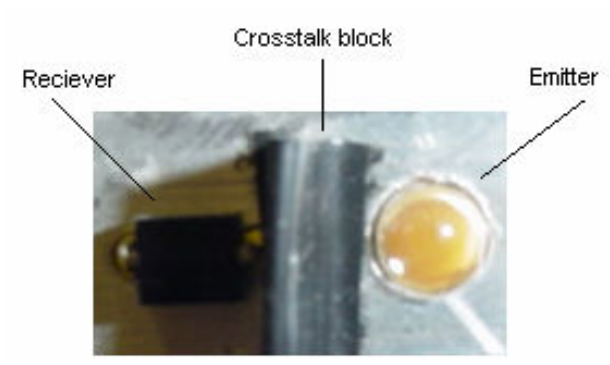

Figure 6. Proximity Switch

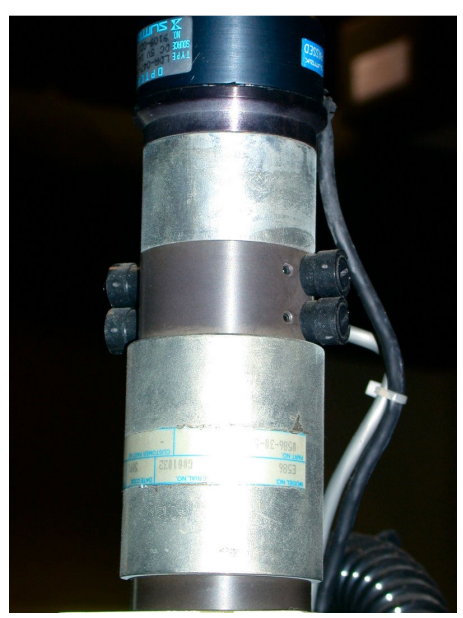

Figure 5. Optical Encoder

\section{Our Approach - The Laboratory Experiences}

We opted to use the "studio" approach for our course. Accordingly, in our approach lecture and laboratory portions of the class were not disjointed, but were combined. There were two aspects to this combination. The first was that both lecture and laboratory activities took place in the same physical location. Secondly, the lecture and laboratory portions were not consigned to pre established, discrete time periods. Laboratory activities were conducted when an ongoing lecture discussion "naturally" led to that activity. This approach ensured the obvious connection between lecture and laboratory.

To start with, the students began by experimenting with the tabletop Microbot. They were divided into teams and the teams competed with each other in having the robot accomplish a task, like stacking cubical blocks, that were prelocated, at a new location. The objective function of the competition was the least time for the task. Students were greatly enthusiastic and enjoyed this fun activity. As different teams competed they were experimenting with different speed settings for the robot and its consequences. When the lecture resumed the students had several questions to ask. Some of these include:

- Why was our robot's motion "jerky" while our neighboring robot's motion smooth?

- How accurately can the robot position the blocks?

- How would the robot know if it has placed the block in the exact location?

- What may be done to improve the situation if the robot has misplaced by a small amount?

- Why does the robot move in small jerky steps with noise?

These questions permitted a very simple and introductory discussion on servomechanisms, sensors, actuators, resolution, accuracy, open loop control and closed loop control. Thus, at the 
end of the first class, students had an upbeat attitude, thought that the course was cool, and thought that it had practical utility. In contrast, the authors can recall that at the end of their first day experience; wherein they had been exposed to the theoretical modeling of mechanical, electrical, thermal, and fluid systems; they felt that they were about to embark on yet another course on differential equations and Laplace transforms.

The next set of laboratory activities involved the Mercury robot and an Allen Bradley programmable logic controller (PLC), whereby students move up to sequential control theory. To begin with the robot was connected to compressed air supply, but not connected electrically to the PLC.

The robot's exterior covers were opened upon to display the limit switches and solenoids. The solenoids were manually excited and the resulting air cylinder movement was demonstrated. Students observed how the limit switches at the end of travel audibly clicked when they were turned on. Student queries about how this robot could be automatically run, resulted in the introduction of sequential control using PLC's and the associated ladder diagram programming. Over the next week the students wrote several ladder diagrams of increasing complexity including components such as contacts, coils, timers, counters, etc. They also tested their ladder diagrams using a "simulator" that was available with the PLC. Finally, the students were asked to write a ladder diagram to automatically sequence the manipulator through a predefined set of motions. Once the ladder diagram was tested using the simulator, the robot was cable linked to the PLC, connected to the compressed air supply and the ladder diagram was run. The students noticed how the PLC would not "run" until a safety mat was connected to the PLC. This in turn introduced the concept of interlocks. In this section of the course, students envision the control architectures that are common in the industry. Emphasis in teaching is on the sequential manner of autonomous operation, entailing load/unloading, assembly, and testing.

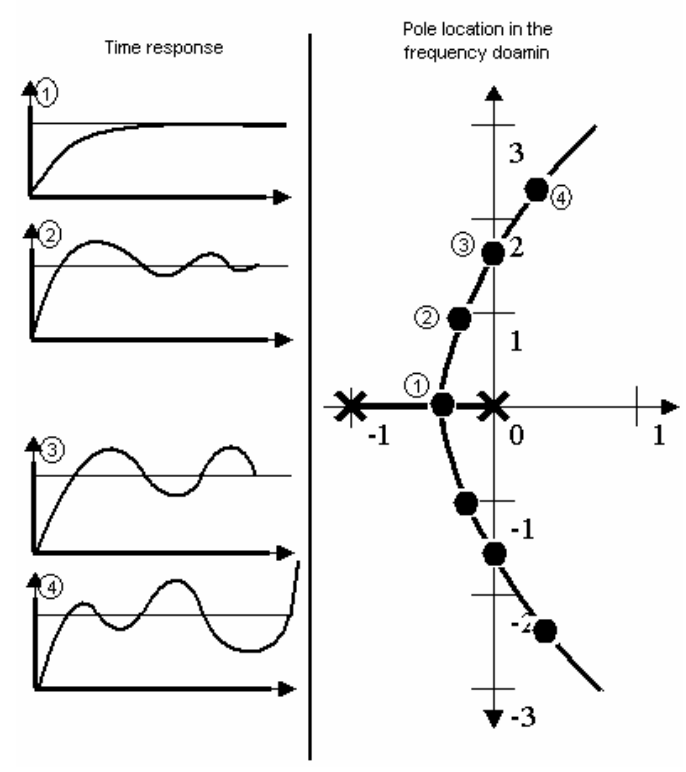

Figure 7: A Chart Used for the Stability 
One of the most challenging aspects of pedagogy in a controls course is the insurance of student comprehension of the stability concept. Our experience indicates that prior exposure to vibration theory helps students comprehend the stability lecture better. This particular part of lecture entails mainly the relationship between the time domain response and the frequency domain pole and zero location. To begin with, a chart similar to the illustration in Figure 7 is used.

Using such chart in conjunction with lab activity, students grasp stability theory in a shorter period. Finally, the relationship between the stability of a dynamic system in time domain and the pole and zero location in the frequency domain are supported further in theory.

\begin{tabular}{|c|c|c|}
\hline $\begin{array}{l}\text { Item } \\
\text { No. }\end{array}$ & Lecture Topic & Laboratory Activity \\
\hline 1 & Introduction & Micro robot (dynamics problem) \\
\hline 2 & $\begin{array}{l}\text { Types of control } \\
\text { Analog/digital } \\
\text { Regulator / follow-up } \\
\text { Sequential } \\
\text { Servo }\end{array}$ & $\begin{array}{l}\text { Sequential control (mercury robot) } \\
\text { Servo control (Jupiter robot) }\end{array}$ \\
\hline 3 & $\begin{array}{l}\text { The common elements of systems components } \\
\text { Four common elements } \\
\text { Electrical, Mechanical, Liquid, Thermal system }\end{array}$ & \\
\hline 4 & $\begin{array}{l}\text { Laplace transforms and D.E. } \\
\text { Laplace transforms } \\
\text { Inverse Laplace transforms } \\
\text { Initial/final value theorems }\end{array}$ & \\
\hline 5 & $\begin{array}{l}\text { Measuring instrument characteristics } \\
\text { Fundamental statistics } \\
\text { Operation characteristics } \\
\text { Static characteristics } \\
\text { Dynamic characteristics }\end{array}$ & Optical encoder, LVDT \\
\hline 6 & Position, motion, force sensors & $\begin{array}{l}\text { Transducers } \\
\text { Potentiometers } \\
\text { Tachometer Generators } \\
\text { Resolvers and Encoders } \\
\end{array}$ \\
\hline 7 & Switches, actuators, valves, heaters & $\begin{array}{l}\text { Drive systems } \\
\text { Motors and Power Amplifier } \\
\text { Control Amplifiers }\end{array}$ \\
\hline 8 & $\begin{array}{l}\text { Control of continuous processes } \\
\text { P, PI, PID control }\end{array}$ & $\begin{array}{l}\text { Control systems } \\
\text { Rotary Position Servo } \\
\text { Rotary Velocity Servo }\end{array}$ \\
\hline 9 & $\begin{array}{l}\text { Process characteristics } \\
\text { Integral, first-order, second-order process }\end{array}$ & \\
\hline 10 & $\begin{array}{l}\text { Method of analysis } \\
\text { Body plot } \\
\text { Root locus }\end{array}$ & $\begin{array}{l}\text { Jupiter robot } \\
\text { Setting dynamic performance } \\
\text { Servo dynamic problems } \\
\text { Servo stability problems }\end{array}$ \\
\hline
\end{tabular}

Table 1. Correlation Between Lecture and Laboratory Activities. 
Table 1 shows the correlation between lecture topics and corresponding laboratory activities. As is shown in Table 1, 70\% of all lecture topics are matched up with lab activities by utilizing either robots or the AMATROL ${ }^{\circledR}$ electro-hydraulic servo training system.

Consistent with approach adopted for the rest of the course, we had designed hands-on activities to help further illustrate the stability theory. Toward this end, the last set of laboratory activities involved the Jupiter robot (refer Table 1, item \#10). This servomotor driven robot uses optical encoders in each of its four axes of movement to provide feedback signals for the closed loop control. The Jupiter robot also used proximity sensors to provide for the homing processes and safety mats to ensure personnel safety. The closed loop control Jupiter robot provided opportunities for students to experiment with servo stability and dynamic problems. Some of the servo problems that students experimented include: overshooting on stopping, low frequency oscillation, high frequency oscillation, noisy servo, unstable servo and cogging. By suitably adjusting robot parameters such as resolution, rate integral gain, rate proportional gain, following error limit, acceleration time constant, position time constant, and average torque trip level students were able to optimize and stabilize robot performance. These laboratory activities helped students "see" the relevance of a lot of theoretical and mathematical concepts that were involved in dynamic stability based lecture discussions.

\section{$\underline{\text { Evaluation }}$}

During the first offering of the controls course, no laboratory sessions were incorporated. Thus, the course was one hundred percent taught as a lecture. Formal student evaluations, informal comments, and the level of student participation in the lectures suggested a low level of interest and an inability to comprehend the practical value of controls engineering in manufacturing. This feedback primarily encouraged the authors to adopt the approach presented in the paper. Detailed evaluations have been planned for the end of the Spring 2004 semester. Informal student responses and class attitudes have been considerably positive in comparison to the first time the course was offered.

\section{$\underline{\text { Conclusions }}$}

Due to the applications nature of Manufacturing Engineering and Engineering Technology programs we had designed an introductory controls engineering course that featured pedagogical approaches that differed from traditional approaches to teaching this subject. Specifically, we had decided to use robots as means to present "hands-on" laboratory experiences for our students. Preliminary student responses to our approach have been very enthusiastic. They seem to assimilate control systems theory very well and are able to internalize the practical need for controls theory. Also, this approach has led to their (students') discovering the fundamental relationships between control systems theory and computer aided manufacturing. 


\section{$\underline{\text { Reference }}$}

[1] Benjamin C. Kuo, Farid Golnaraghi, "Automatic Control Systems",John Wiley \& Sons; 8th edition Sep. 2002

[2] Katsuhiko Ogata, "Modern Control Engineering (4th Edition)", Prentice Hall; 4th edition, Nov. 2001

[3] http://www.coe.neu.edu/set/listserv.html

\section{Dugan Um}

Dugan Um achieved his Ph.D in Mechanical Engineering in the University of Wisconsin at Madison. After his dissertation, he joined Caterpillar Inc as a research engineer. After about 4 years of industrial experience he started teaching career in the Texas State University at San Marcos. He is currently an assistant professor at the Department of Technology.

\section{VEDARAMAN SRIRAMAN}

VEDARAMAN SRIRAMAN is Professor and Assistant Dean in the College of Science at Texas State University-San Marcos. His research interests and publications are in the area of engineering pedagogy and manufacturing engineering. 